\title{
Clinical profile of patients with infantile spasms
}

\author{
Wael hayel khreisat \\ Queen Rania hospital for children \\ King Hussein medical center \\ Royal medical services \\ Amman, Jordan
}

\begin{abstract}
Objective: The present study was done in order to obtain a baseline profile of infantile spasms and associated neurological disorders

Patient and methods:. The study included 50 patients with infantile spasm in Queen Rania Hospital for children in Jordan. The following data were obtained: sex, age of onset and presentation, details of seizure, family history of epilepsy, significant pre-/peri/post-natal insults, neuro imaging evaluation , detailed neurological and neuro developmental, assessment were done by. Broad categories of possible etiologies were used the results were recorded for further study.

Results: Age of onset of infantile spasm ranged from 1 month to 1 year and 6 months, (mean 4.8 months). The mean time of presentation was 9.4 months . A male preponderance was noted (74\%). flexor spasms (52\%) were the commonest. Other types of seizures also accompanied infantile spasm in $44 \%$ children. (84\%) were born of normal delivery, History of birth asphyxia was obtained in $48 \%, 3$ (6\%) had positive family history Developmental delay was recognized prior to onset of spasms in $52 \%$. microcephaly was the commonest associated problem, Imaging studies of the brain revealed abnormality in 18 patients. $78 \%$ patients symptomatic and $22 \%$ as cryptogenic..
\end{abstract}

Conclusion: The pattern of infantile spasm in our country do not differ from that of developed countries, further researches is required to prevent both chronic epilepsy and psychomotor retardation and .preventive measurement to prevent birth asphyxia is recommended

Keyword: infantile spasm, seizures, epilepsy

\section{Introduction}

Infantile spasms represent a seizure disorder with unique clinical and electroencephalographic features and a poor prognosis including chronic intractable epilepsy and psychomotor retardation.; the incidence of infantile spasms is considered to be 0.16 to 42 per 1000 live births (Cowan and Hudson; 1991 ), it associated with the particular EEG pattern, hypsarrhythmia (Shields ; 2006)

Early diagnosis with a careful diagnostic evaluation and proper therapy can obtain a normal development or a much improved situation in some cases (Dreifuss 1981) ,This spasm is also referred in literature as massive spasms, Salaam tics, infantile myoclonic seizures . It has been classified in the category of generalized seizures with specific EEG characteristics. Focal seizures as well as focal lesions can also be present (Dulac et al , 1994 )

Epileptic spasms (ES) are define as seizures characterized by brief axial contraction, in flexion, extension or mixed, symmetric or asymmetric, lasting from a fraction of a second to 1-2 s (Fusco and Vigevano , 1993 ) it occurs almost exclusively during the first year of life, mostly between four and seven months of age. It may be present in clusters do not appear generally after one to two years of age (Gobbi , 1987 )although late onset up to seven to eight years of age has been reported in rare cases (Riikonen, 2001) 

Although the epileptogenic mechanisms of infantile spasms is not well understood, an etiologic diagnosis can be identified in more than $70 \%$ of cases (Rantala , 1999 ), which may lead to a specific therapy that can have a dramatic influence on the outcome of the patient

The present study was done to obtain a baseline profile of infantile spasms who are at regular visit at pediatric neurology clinic or admitted to neurological department of queen rania hospital for children, focused on age of onset, type of seizure, associated neurological deficits and the etiology .

\section{Patients and Methods}

Subjects included in this study were fifty infants suffering infantile spasm, who attended pediatric neurology clinic or from the inpatient services of neurological department of queen rania hospital for children in Jordan , the following data were collected : sex, age of onset, age of presentation to our center , details of seizure, , family history of epileptic disorders (1st and 2nd degree relatives), significant pre-/peri/post-natal insults .

Detailed neurological, medical, neurodevelopment assessment was done by pediatric neurologist. Broad categories of possible etiologies were used. The diagnosis of birth asphyxia required the documentation of moderate to severe encephalopathy. Brain atrophy was diagnosed when ventricular dilatation with widening of the sulci is present.

Acquired brain insult included patients with birth asphyxia, intracranial hemorrhage, trauma, vascular etiology, toxins ( kernicterus) and infectious or immunologic causes.

An infectious etiology required objective cerebrospinal fluid finding or immunological evidence of intrauterine infection.

Neuroimaging MRI/CT or both were done for more than $90 \%$ of patients. Magnetic resonance imaging was the preferred investigation but those who could not tolerate it because of their medical condition; a computerized tomography scan was done instead.

The response to treatment was classified as follows: complete (no relapse observed after last spasm for the entire follow-up period), transient (relapse of spasms after at least a 7day spasm free period) and no response

Infantile spasms were classified into symptomatic and cryptogenic groups. Cryptogenic group is characterized by (1) normal pregnancy and birth, (2) normal development before the onset of spasm and absence of neurological abnormalities at the onset of spasm, (3) absence of any other types of seizure before the onset of spasm, and (4) normal laboratory, computerized tomography (CT), and MRI findings at onset [6].

\section{Results}

Age of onset of infantile spasm ranged from 1 month to 1 year and 6months, (mean 4.8 months). The age at the time of presentation ranged from 1.5 months to 4.5 years (mean 9.4 months). Distribution of infantile spasm according to age of onset Figure 1. A male preponderance was noted $(74 \%)$. Clinical seizure pattern was typical in most with majority presenting with flexor spasms. (52\%). Most of them more than 10 times per a day. $44 \%$ infants have other types of seizures these were focal (16\%), generalized $(20 \%)$ and others $(8 \%)$. In $96 \%$ of cases IS where classically maxi-mum on awakening from sleep;. History of birth asphyxia was obtained in $48 \%$, , The etiology of infantile spasm in this study showed in Table 1. Among the 50 patients, $3(6 \%)$ had a first- degree relative clinical profile is seen in Table II.

Developmental delay was recognized prior to onset of spasms in 52\% and after the onset of spasms in 34\%. Associated problems like microcephaly, visual abnormalities and hearing problems were shown in Table III

Imaging studies of the brain (computerized tomography (CT) or magnetic resonance imaging (MRI)) were done in 45 patients and revealed abnormality in 18 patients the findings are shown in Table 4 and Figures 2, 3,4 and 5

Symptomatic patients were $78 \%$ and $22 \%$ as cryptogenic. 



\section{Discussion}

On the basis of records from pediatric neurology clinic and department, this study has provided important baseline information on the etiology, clinical presentation and associated developmental problems with infantile spasm Infantile spasm onset in our series occurs mainly in infancy with the mean age of 3.4 months although it was reported that the peak of age of onset is in the middle of the first year of life, onset may be delayed to after the age of 1 year in $2 \%$ of the patients, from the newborn period to the age of 4 years (Bednarek, 1998 ) . The reason for the late onset in some patients appears clearly when the patient has a postnatal lesion, but is less clear when the patient has a congenital brain lesion. In addition, the location of the lesion in the cortex determines in part the age of onset, and lesions affecting the posterior half of the brain often generate earlier onset of seizures than those affecting the anterior half.

Although many studies have reported a male preponderance of infantile spasms as seen in the present study male to female ratio 2.8 to 1 , frost and hrachovy reported an excess of female subjects with this disorder (Frost and Hrachovy, 2003). It has been suggested that the observed male predominance observed in some studies may simply reflect a larger proportion of male patients in the referral population (Brna et al., 2001).

Spasms can be of the flexor or extension or mixed flexor extension types of the neck, trunk, arms and legs (Chugani ,2002 ), among the clinically observed types of spasms, flexor types were most frequent which is similar to other reports (Lombroso, 1983 ,Dulac 1997). Most infants with this disorder have more than one type of spasm (92\%, Kellaway et al., 1979; 100\%, King et al., 1985) while in this study it forms $44 \%$.

Seizures may occur before the onset of infantile spasms (Yamamoto etal 1988, Velez et al 1990 ) Approximately one third to one half of patients with epileptic spasms have other seizure types preceding or accompanying the onset of the spasms (Lombroso,1983 ). In this studied group, $36 \%$ had other types of seizures prior to the onset of infantile spasms With focal or generalized seizure, delay in giving specific diagnosis and treatment occurred which might be one of the contributing factors for poor outcomes in some patients.

Developmental delay was recognized prior to onset of spasms in 52\% and after the onset of spasms in $34 \%$. Developmental delay predates the onset of spasms in about $70 \%$ of children.( Arzimanoglou et al 2004 ) Disappearance of social smile, loss of visual attention,( Kramer , 1997 ) or autistic withdrawal are often observed with the onset of spasms.

For some patients with spasms, psychomotor retardation was present from birth and epilepsy began several months later, and the question of the real age of onset of the epilepsy is raised, and the question of the contribution of hypsarrhythmia overlooked during a long period of time to the generation of psychomotor delay has to be addressed ( Villeneuve, 1998 ) . On the other hand, some patients do not experience deterioration, and seem to continue developing. However, in these cases, treatment effective on the spasms and the EEG abnormalities soon shows that development velocity before treatment was not as good as following it.

The percentage of cases having a positive family history for epilepsy of any type has ranged from none (Liou et al., 2001) to 33\% (Druckman and Chao, 1955). However, when only larger series (studies with more than 100 patients) are analyzed, the range is much lower: $1 \%$ to $7 \%$ (; Lombroso, 1983) which is consist with our finding, true familial occurrence of infantile spasms has been documented in a number of families, and various underlying causes, including some neurologic syndromes with a genetic basis, have been identified (Howitz, 1980; Sugaiet al., 2001).

Although the list of specific diseases potentially causing infantile spasms is enormous, diagnostic evaluation does not necessarily have to be exhaustive. A recent study examined the effectiveness of using a staged diagnostic evaluation for infantile spasms ( Trasmonte and Barron,1998)

It is therefore important to establish a protocol management of patients in order to obtain a precise etiology. The reported percentage of total infantile spasms cases classified as symptomatic has risen over the years as etiologies have become identified more readily. In the early 1980 s, most studies found identified symptomatic etiologies in 
approximately $45-60 \%$ of patients ( Matsumoto et al, 1981 ) As seen in our study more recent studies have consistently classified $70-80 \%$ of patients into the symptomatic group

( Rantala and Putkonen, 1999 )

This trend can be attributed mostly to the improved sensitivity of diagnostic testing, especially neuroimaging studies. Magnetic resonance imaging has a higher sensitivity for detecting focal abnormalities in West syndrome patients compared with computed tomography ( Van et al 1993)

Within the symptomatic group the etiologies for infantile spasms have traditionally been divided into prenatal, perinatal, and postnatal causes. As seen in recent study most studies identify prenatal etiologies as the most common, accounting for almost $50 \%$ of symptomatic cases (Kurokawa et al 1980 ) which is consistent with our study, although perinatal causes have been reported to be on the rise (Watanabe, 1998 )

Regarding the neurological co morbidities associated with infantile spasm microcephaly was the commonest associated finding present in almost $50 \%$ of our cases. In other studies also this has been a significant clinical abnormality, it has been suggested that it denotes the involvement of brain parenchyma even before the onset of IS ( Koul et al 2001 ). Visual impairment has been found in approximately $25 \%$ of cases (Koul et al 2001 ) which is closed to our finding

( Aydinli et al 1998 ) a study on neuroradiological aspects of IS in patients also reported normal CT scans in $17 \%$ and normal MR scans in $18 \%$, while in our study it was abnormal in $6 \%$. MRI is more informative than CT scan as it demonstrates focal cortical and subcortical lesions and white matter lesions better and may also help in prognostication of motor outcome in these cases ( Juhasz et al , 2001 )

Prognosis depends more on the cause than on treatment. Bad prognostic factors include symptomaticity, early onset (younger than 3 months), pre-existing seizures other than spasms, asymmetric EEG, And relapse after initial response to treatment ( Saltik et al 2002 ) . Good prognostic indicators include cryptogenicity, normal brain MRI, typical hypsarrhythmia, rapid response to treatment, and no regression after onset of spasms or its short duration (Kivity , 2004 )

\section{Conclusion and recommendations;}

The results of this study proposed the need for long-term population epidemiological outcome studies. The pattern of infantile spasm in our country do not differ from that of developed countries, preventive measurements regarding birth asphyxia should be initiated 


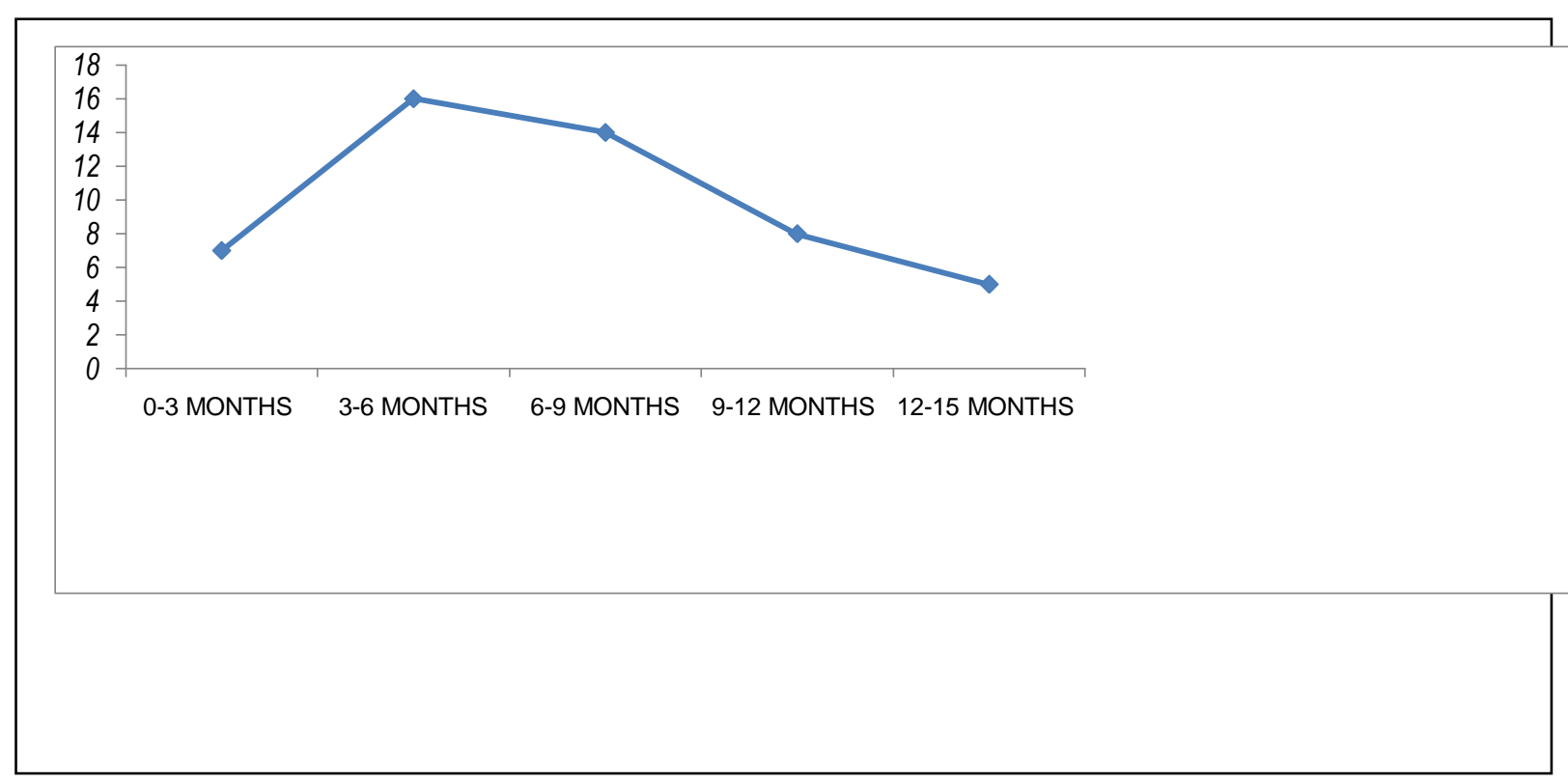

Fig (1) Distribution of infantile spasm according to age of onset

\begin{tabular}{|l|c|c|}
\hline Etiology & $\underline{\text { No }}$ & $\underline{\text { Percent }}$ \\
\hline Cryptogenic & 11 & $22 \%$ \\
\hline CNS infection & 3 & $6 \%$ \\
\hline Birth asphyxia & 24 & $48 \%$ \\
\hline Neuro metabolic & 2 & $4 \%$ \\
\hline Birth trauma & 2 & $4 \%$ \\
\hline $\begin{array}{l}\text { Congenital anomaly of the } \\
\text { brain }\end{array}$ & 6 & $12 \%$ \\
\hline Neuro coetaneous & 1 & $2 \%$ \\
\hline TORCH & 1 & $2 \%$ \\
\hline
\end{tabular}

Table (1) : The etiology of infantile spasm 

Clinical profile...

\begin{tabular}{|l|c|c|}
\hline Characteristic & no & Percent \\
\hline Male & 37 & $74 \%$ \\
Female & 13 & $26 \%$ \\
& & \\
\hline Positive Family history & 3 & $6 \%$ \\
\hline Seizure pattern & & \\
Flexor & 21 & $42 \%$ \\
Extensor & 11 & $22 \%$ \\
Mixed & 18 & $36 \%$ \\
& & \\
\hline Number of spasm / day & & \\
5 & 12 & $24 \%$ \\
5-10 & 18 & $36 \%$ \\
More than 10 & 20 & $40 \%$ \\
\hline Associated seizures & & \\
Generalized seizure & 10 & $20 \%$ \\
Focal seizure & 8 & $16 \%$ \\
Others & 4 & $8 \%$ \\
\hline Symptomatic & $78 \%$ \\
Cryptogenic & 39 & $22 \%$ \\
\hline Reponses to treatment & 11 & $30 \%$ \\
Complete & 15 & $70 \%$ \\
Transient & 35 & $54 \%$ \\
\hline Radiological finding & & $36 \%$ \\
Normal & 27 & $10 \%$ \\
Abnormal & 18 & 5 \\
Not done & & \\
\hline
\end{tabular}

Table II: Clinical profile of studied cases

\begin{tabular}{|l|c|c|}
\hline Neurological disorder & No & Percent \\
\hline Microcephaly & 26 & $52 \%$ \\
\hline Hypotonic & 12 & $24 \%$ \\
\hline Spastic & 18 & $36 \%$ \\
\hline Visual defect & 15 & $30 \%$ \\
\hline Deafness & 12 & $24 \%$ \\
\hline Dysmorphic & 2 & $4 \%$ \\
\hline Developmental delayed & 26 & $52 \%$ \\
\hline Developmental regression & 17 & $34 \%$ \\
\hline Hypo pigmentation & 2 & $2 \%$ \\
\hline
\end{tabular}

Table III : Associated neurological disorders 


\begin{tabular}{|l|c|c|}
\hline FINDING & NO & PERCENT \\
\hline Abnormal & 27 & $54 \%$ \\
\hline Cerebral atrophy & 8 & $16 \%$ \\
\hline Stroke & 4 & $8 \%$ \\
\hline Malformation & 3 & $6 \%$ \\
\hline White matter disorders & 2 & $4 \%$ \\
\hline Calcifications & 1 & $2 \%$ \\
\hline
\end{tabular}

Table IV: Brain imaging finding in patient with IS



figure (3) : Brain MRI : extensive periventricular hyperintense signal suggestive of leuckodystrophy

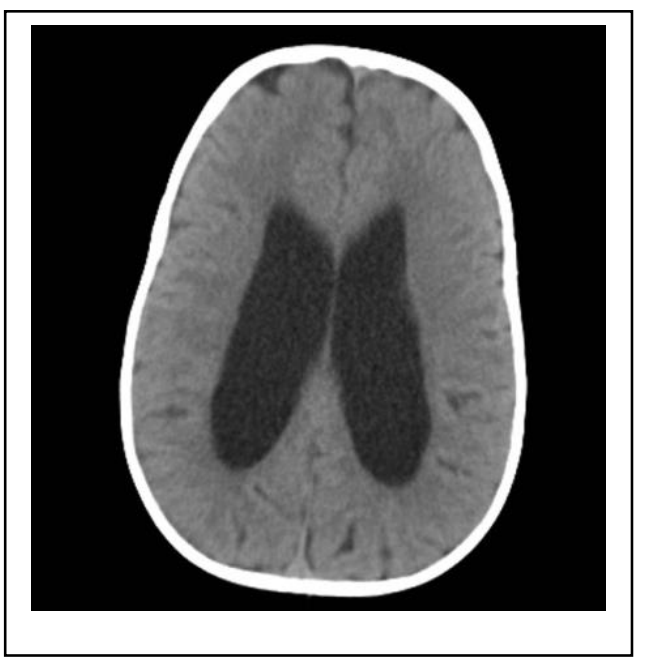

Figure ( 5) :Brain CT scan: dilated ventricular system with loss of white motor core result of birth asphyxia

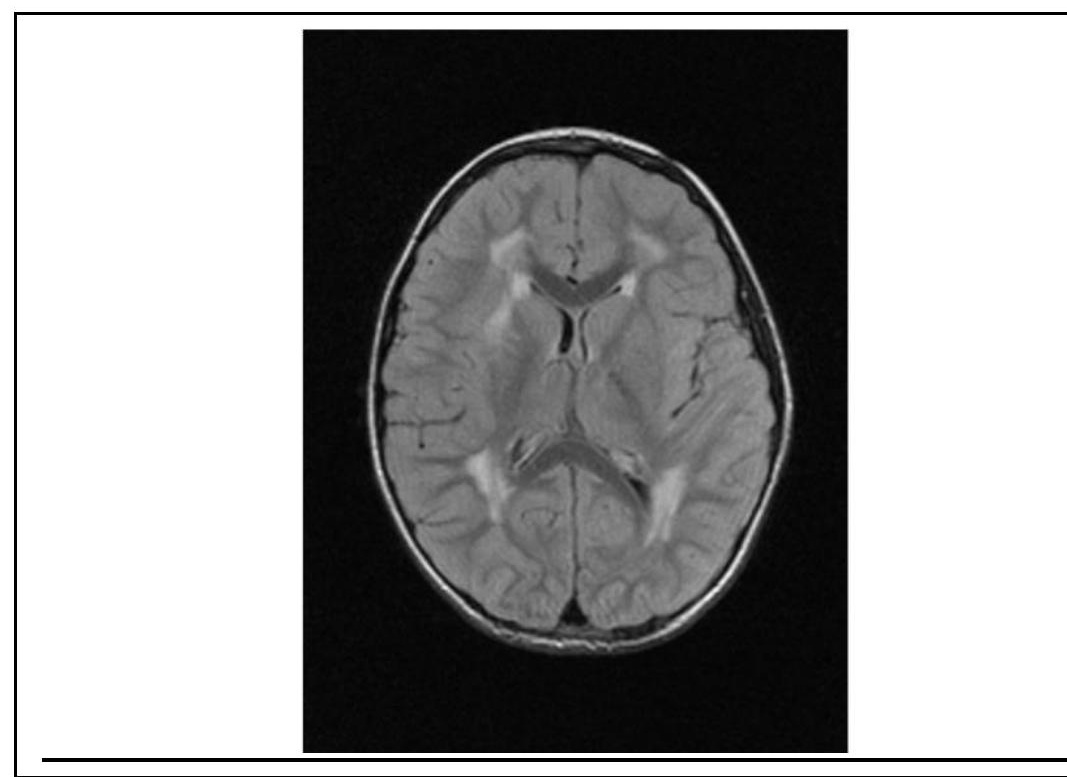

figure (2): White matter hyperintense suggestive of leuckodystrophy

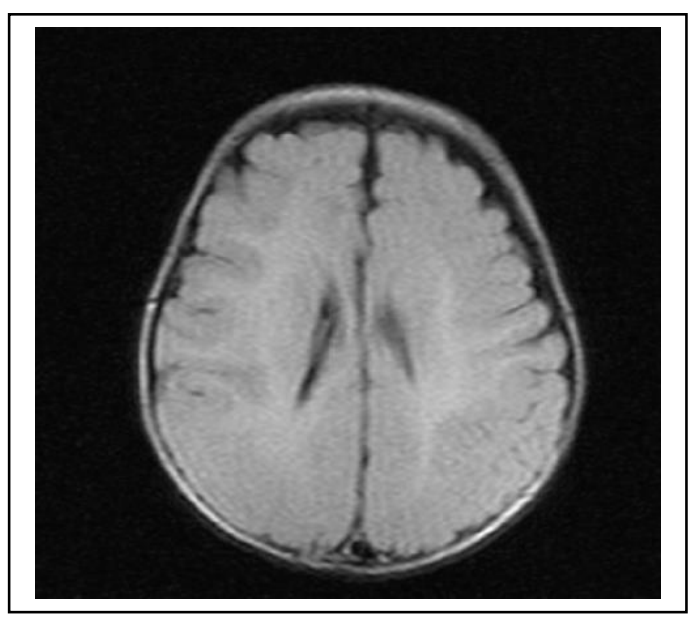

Figure (4): Atrophic changes involved bitemporal area 


\section{Reference:}

Arzimanoglou A, Guerrini R, Aicardi J .( 2004). Epilepsy in children, 3rd edn. Philadelphia: Lippincott Williams \& Wilkins,.

Aydinli N, Catiskan M, Ozmen N, Tonguc E. (1998). Neuroradiological aspects of West syndrome. Pediatr Neurol;19:211-6.

Bednarek N, Motte J, Soufflet C, Plouin P, Dulac $\boldsymbol{O}$. (1998) . Evidence of late onset infantile spasms. Epilepsia;39:32-39.

Brna PM, Gordon KE, Dooley JM, Wood EP. (2001) .The epidemiology of infantile spasms. Can J Neurol Sci; 28:309-12.

Chugani HT (2002): Pathophysiology of infantile spasms. Adv Exp Med Biol, 497:111-121.

Cowan LD, Hudson LS. (1991). The epidemiology and natural history of infantile spasms. ,J7 Child Neurol; 6: 355-64.

Dreifuss FE. (1981): Proposal for revised clinical and electroencephalographic classification of epileptic seizures. Epilepsia, 22:249-260.

Druckman R, Chao D. (1955).Massive spasms in infancy and childhood..Epilepsia;4:61-72.

Dulac O, Chugani HT, Dalla Bernardina B, eds. 1994 ,Infantile spasms and West syndrome. London: W.B. Sanders,

Dulac $O$ 1997. Infantile spasms and West syndrome. In: Engel J, Pedley TA, editors. Epilepsy: comprehensive textbook, Philadelphia, PA: Lippincott-Raven,. pp. 2277-2305.

Frost JD Jr, Hrachovy RA. Infantile spasms. 2003 , Boston: Kluwer Academic Publishers,

Fusco L, Vigevano F1993. Ictal clinical electroencephalographic findings of spasms in West syndrome. . Epilepsia; 34: 671-8.

Gobbi G, Bruno L, Pini A, Rossi PG, Tassinari CA. 1987 Periodic spasms: an unclassified type of epileptic seizure in childhood. . Dev Med Child Neurol; 29: 766-75

Howitz P. 1980.Infantile spasms in siblings..Dan Med Bull;27:272-4.

Juhasz c, Chugani HT, Muzik O, Chugani DC2001. Neuroradiological assessment of brain structure and function and its implication in the pathogenesis of West syndrome.. Brain Dev;23:488-95.

Kellaway P, Hrachovy RA, Frost JD Jr, Zion T. 1979. Precise characterization and quantification of infantile spasms.. Ann Neurol;6: 214-8.

King DW, Dyken PR, Spinks IL Jr, Murvin AJ. 1985.Infantile spasms: ictal phenomena..Pediatr Neurol;1:213-8.

Kivity S, Lerman P, Ariel R, et al. 2004. Long-term cognitive outcomes of cohort of children with cryptogenic infantile spasms treated with high-dose adrenocorticotropic hormone. Epilepsia; 45: 25562.

Koul R, Chacko A, Cherian E. 2001. West syndrome: a university hospital based study from Oman. Brain Dev;23:586-92.

Kramer U, Sue W-C, Mikati M. 1997.Focal features in West syndrome indicating candidacy for surgery. Pediatr Neurol; 16: 213-17

Kurokawa T, Goya N, Fukuyama Y, Suzuki M, Seki T,Ohtahara S. 1980. West syndrome and Lennox-Gastaut syndrome: A survey ofnatural history. Pediatrics;65:81-8.

Liou HH, Oon PC, Lin HC, Wang PJ, Chen TH. 2001. Risk factors associated with infantile spasms: a hospital-based case-control study inTaiwan. Epilepsy Res;47:91-8.

Lombroso CT 1983.: A prospective study of infantile spasms: clinical and therapeuthic consideration. Epilepsia, 24:135-158.

Matsumoto A, Watanabe K, Negoro T, et al. 1981. Long-term prognosis after infantile spasms: A statistical study of prognositic factors in 200 cases. Dev Med Child Neurol;23:51-65.

Rantala H, Putkonen T. 1999 . Occurrence, outcome, and prognostic factors of infantile spasms and Lennox-Gastaut syndrome. Epilepsia;40:286-9.

Riikonen R. 2001. Epidemiological data of West syndrome in Finland. Brain Dev;23:539-541.

Saltik S, Kocer N, Dervent A. 2002. Informative value of magnetic resonance imaging and EEG in the prognosis of infantile spasms. Epilepsia; 43: 246-52.

Shields WD. 2006: Infantile spasms: little seizures, BIG consequence. Epilepsy Curr, 6:63-69.

Sugai K, Fukuyama Y, Yasuda K, et al. 2001. Clinical and pedigree study on familial cases of West syndrome in Japan. Brain Dev;23: 558-64

Trasmonte JV, Barron TF. 1998. Infantile spasms: A proposal for a staged evaluation. Pediatr Neurol;19:368-71.

Van Bogaert P, Chiron C, Adamsbaum C, Robain O, Diebler C, Dulac O. 1993 .Value of magnetic resonance imaging in West syndrome of unknown etiology. Epilepsia;34:701-6.

Velez A, Dulac O, Plouin P. 1990 . Prognosis for seizure control in infantile spasms preceded by other seizures. Brain Dev;12:306-309

Villeneuve N, Soufflet C, Plouin P, Chiron C, Dulac O. 1998 ,Traitement des spasmes infantiles par vigabatrin en premie 're intention et mono-the 'rapie: a propos de 70 nourrissons. Arch Pediatr;5:731-738.

Watanabe K. West syndrome . 1998: Etiological and prognostic aspects.. Brain Dev;20:1-8.

Yamamoto N, Watanabe L, Negoro T. 1988. Partial seizures evolving to infantile spasms. Epilepsia;29:34-40. 



\title{
الملف السريزي للمرضى الذين يعانون من تشنجات الرضع
}

\author{
وائل خريسات \\ أخصائي أعصاب الأطفال مستشفى الملكة رانيا للأطفال / الأردن
}

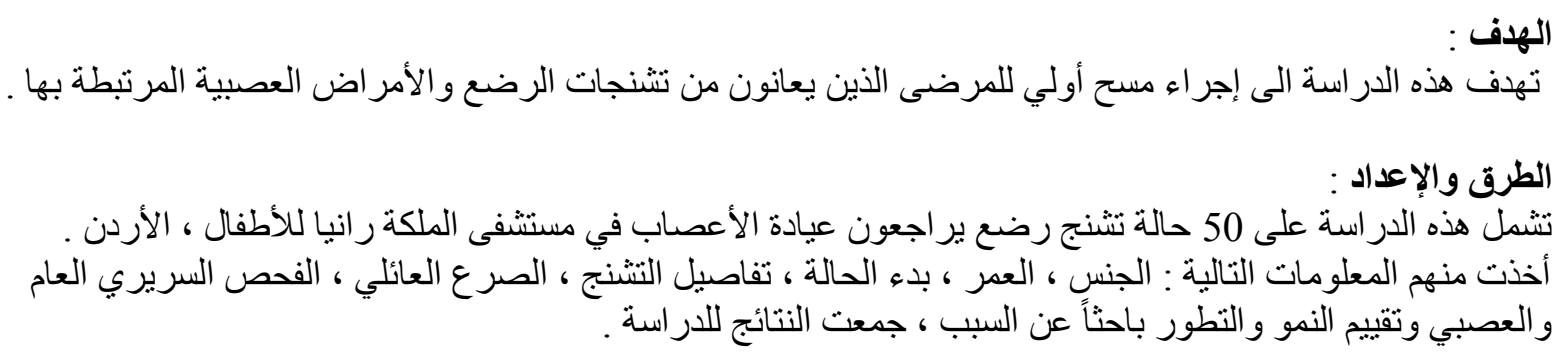

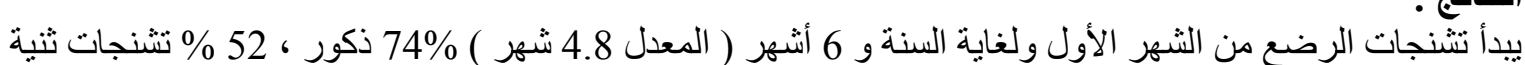

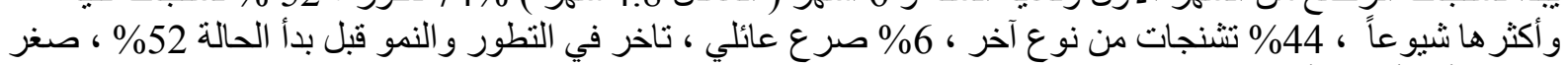



حالإستتنتجات التشات التوصيات :

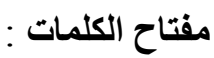
تشنجات الرضع ، التشنج ، الصرع . 